\title{
Enhancing catalytic performance of activated carbon supported Rh catalyst on heterogeneous hydroformylationof 1-hexene via introducing surface oxygen-containing groups
}

\author{
Minghui Tan ${ }^{1,2}$, Ding Wang ${ }^{3}$, Peipei $\mathrm{Ai}^{2}$, Guoguo $\mathrm{Liu}^{2}$, Mingbo Wu ${ }^{1 \text {,*** }}$, Jingtang Zheng ${ }^{1, * * *}$, \\ Guohui Yang ${ }^{2,4}$, Yoshiharu Yoneyama ${ }^{2}$, Noritatsu Tsubaki ${ }^{2, *}$ \\ ${ }^{1}$ State Key Laboratory of Heavy Oil Processing, China University of Petroleum, Qingdao 266580, PR China. \\ ${ }^{2}$ Department of Applied Chemistry, School of Engineering, University of Toyama, Gofuku 3190, Toyama 930-8555, \\ Japan. \\ ${ }^{3}$ College of Materials Science and Engineering, University of Shanghai for Science \& Technology, Shanghai, \\ 200093, China \\ ${ }^{4}$ State Key Laboratory of Coal Conversion, Institute of Coal Chemistry, Chinese Academy of Sciences, Taiyuan, \\ 030001, China
}

\begin{abstract}
Activated carbon supported rhodium (Rh/AC) catalysts with different amounts of oxygen-containing functional groups were prepared by nitric acid $\left(\mathrm{HNO}_{3}\right)$ treatment at varied temperatures. Thermal analyses of $\mathrm{Rh} / \mathrm{AC}$ catalysts with or without this acidic treatment were characterized by thermogravimetric analysis (TGA) and temperature programmed desorption (TPD). The change of surface oxygen-containing functional groups was characterized by Fourier transform infrared spectrometry (FTIR) and X-ray photoelectron spectroscopy (XPS). These characterization results indicated that the amount of oxygen-containing functional groups increased with the treatment temperature. The influence of these oxygen-containing functional
\end{abstract}

${ }^{*}$ Corresponding Author: Phone: +(81)-76-445-6846. Fax: +(81)-76-445-6846. E-mail: tsubaki@eng.u-toyama.ac.jp; ${ }^{* *}$ Corresponding Author: E-mail: wumb@upc.edu.cn;

${ }^{* * *}$ Corresponding Author: E-mail: jtzheng03@163.com. 
groups on the products selectivities in heterogeneous hydroformylation reaction was investigated in detail. These abundant functional groups were benefited to improve the selectivity of $\mathrm{n}$-heptanal, resulting in higher $\mathrm{n} / \mathrm{i}$ (normal to iso) ratio of heptanal. The $\mathrm{Rh} / \mathrm{AC}$ catalyst being treated at $80{ }^{\circ} \mathrm{C}$ had the highest $\mathrm{n} / \mathrm{i}$ ratio of 2.3 , due to the maximum amount of oxygen-containing functional groups, which was almost double to that of raw $\mathrm{Rh} / \mathrm{AC}$ catalyst. Moreover, abundant functional groups on catalyst suppressed hydrogenation of hexene, decreasing the selectivity of hexane from $4.9 \%$ of raw $\mathrm{Rh} / \mathrm{AC}$ to $0.2 \%$. These findings disclosed that these oxygen-containing functional groups on catalysts played an extremely important role in improving the catalytic performance of heterogeneous hydroformylation reaction, providing a new viewpoint for the studies on heterogeneous hydroformylation.

Keywords: Hydroformylation, Syngas, Aldehyde, Surface modification, Activated carbon

\section{Introduction}

Hydroformylation of alkene is one of the most important homogenous metal-catalyzed reactions.[1-4] Aldehyde is formed by addition of syngas across the double carbon bond $(\mathrm{C}=\mathrm{C})$ of 1-alkene. Hydroformylation of 1-alkenes produces the mixed aldehydes, linear n-aldehydes (n) and branched i-aldehydes (i). But only n-aldehydes are optimized products in commodity applications.[5, 6]

The traditional hydroformylation of 1-alkene usually uses homogeneous catalysts such as the rhodium-ligand complexes, which have high catalytic activity and selectivity.[7-10] But they also have some drawbacks, such as very high pressure, noble metal loss, catalyst/product separation difficulty and so on.[11] Therefore, the development of different heterogeneous catalyst systems to replace homogeneous catalysts is promising. Heterogenizations of 
homogeneous catalysts in aqueous phase, ionic liquids or fluorous phase have been employed for hydroformylation in biphasic systems.[12-15] Immobilization of homogeneous species onto the solid Si has also been investigated for heterogeneous hydroformylation.[11] These catalysts can be easily separated and recycled from the reaction mixtures, but the catalytic active species in these systems are usually less catalytically active than their homogeneous analogues.[16] Moreover, the synthesis procedures of these catalysts are complicated. Thus, extensive efforts have been made to exploit solid supported rhodium catalysts with high active by simple preparation method. So far, many solid catalysts, such as $\mathrm{SiO}_{2}, \mathrm{Al}_{2} \mathrm{O}_{3}$, zeolite, MOF or carbon materials supported $\mathrm{Rh}$ catalysts, have been investigated for the 1-alkene hydroformylation, which exhibit high reaction activity and aldehyde yields.[17-20] But the selectivity of n-aldehyde is always unsatisfactory. The low selectivity of $n$-aldehyde is mainly derived from the competitive production of i-aldehyde from hydroformylation of terminal alkene (b, Scheme 1), hydrogenation of alkene (c, Scheme 1), isomerization (the migration of $\mathrm{C}=\mathrm{C}$ ) of terminal alkene (d, Scheme 1), and hydroformylation of internal alkene (e, Scheme 1).

In homogeneous catalysis, the catalyst selectivity can be adjusted by some electron withdrawing aryl substituents, or functional groups such as carboxylic acid, ester or ketone groups).[21-25] For instance, Wakamatsu et al found that the shift of carbon double bond was strongly influenced by the functional groups in functionalized internal alkenes.[22] Casey et al investigated the different effects of aryl substituents linked at equatorial and apical diphosphines ligand on the selectivity of n-aldehyde.[25] In heterogeneous catalyst, the surface properties of catalysts are also very important, such as the surface functional groups, heteroatom doping and hydrophobicity-hydrophilicity balance, which can affect the catalytic activity and product selectivity.[26, 27] However, to our knowledge, the influence of the surface properties on the catalytic performance of heterogeneous hydroformylation is rarely reported. For the previous 
heterogeneous hydroformylation, most researches were focused on the selection of catalyst supports or active metals, while the effect of catalyst surface property was often ignored.

In order to clarify this effect, we selected activated carbon (AC) as the catalyst support, which is easy to tune the surface properties by introducing some surface oxygen-containing functional groups. Generally, $\mathrm{HNO}_{3}$ treatment is a facile and available way for implanting of surface oxygen-containing functional groups on the surface of AC. These functional groups on $\mathrm{AC}$ can act as nucleation sites to anchor metal ions, which is beneficial the dispersion of metal ions. Therefore, $\mathrm{HNO}_{3}$ treatment is often used to pretreat $\mathrm{AC}$ before metal immobilization. Some works used $\mathrm{AC}$ pretreated by $\mathrm{HNO}_{3}$ as support to investigate the effect of these groups on the preparation of catalyst.[27-29] These fixed surface groups could affect the particle size and dispersion of the loaded active metal on $\mathrm{AC}$, and alter catalytic performance consequently. However, these groups introduced by pretreatment, which may play an important role in adsorption and catalysis in reaction, were often removed during the catalyst preparation process accompanied by heating or reduction. Therefore, to investigate the direct influence of these groups on the catalytic reaction, it is necessary to introduce the groups on the final prepared catalyst. Herein, considering the simple modification of $\mathrm{AC}$ and strong resistance of $\mathrm{Rh}$ to $\mathrm{HNO}_{3}$, AC supported $\mathrm{Rh}(\mathrm{Rh} / \mathrm{AC})$ catalyst was treated by $\mathrm{HNO}_{3}$ to introduce surface oxygen-containing groups on its surface. Then, these solid catalysts were applied in hydroformylation of 1-hexene to investigate the influences of these groups on catalytic performance. These treated catalysts with abundant surface oxygen-containing functional groups exhibited enhanced selectivity of n-heptanal.

\section{Experimental}

\subsection{Catalyst preparation}


The $\mathrm{Rh} / \mathrm{AC}$ catalyst was prepared by an incipient wetness impregnation method. The AC (40-60 meshes, Kanto Chemical Co. Inc., Japan) was impregnated by a certain amount of $\mathrm{Rh}\left(\mathrm{NO}_{3}\right)_{3}$ aqueous solution to yield a $5 \mathrm{wt} \% \mathrm{Rh}$ loading. After impregnation, the catalyst precursor was vacuumed at room temperature for $1 \mathrm{~h}$ and dried at $120{ }^{\circ} \mathrm{C}$ for $12 \mathrm{~h}$. Then the sample was calcined at $400{ }^{\circ} \mathrm{C}$ for $2 \mathrm{~h}$ under the nitrogen flow. Finally, the catalyst was reduced by hydrogen at $400{ }^{\circ} \mathrm{C}$ for $10 \mathrm{~h}$. Surface oxidation treatments on the obtained $\mathrm{Rh} / \mathrm{AC}$ catalyst were conducted by being heated in $\mathrm{HNO}_{3}$ solution (35\%) at different temperature for $4 \mathrm{~h}$ with magnetic stirring. After treatment, the catalyst was centrifuged and rinsed with distilled water, and then dried at $60{ }^{\circ} \mathrm{C}$ under vacuum for $12 \mathrm{~h}$. According to the temperature of oxidation treatment, these catalysts were named as $\mathrm{Rh} / \mathrm{AC}-40\left(40{ }^{\circ} \mathrm{C}\right), \mathrm{Rh} / \mathrm{AC}-60\left(60{ }^{\circ} \mathrm{C}\right)$ and $\mathrm{Rh} / \mathrm{AC}-80$ $\left(80{ }^{\circ} \mathrm{C}\right)$.

\subsection{Catalyst characterization}

$\mathrm{N}_{2}$ adsorption-desorption was carried out on Micromeritics ASAP 2020 sorption analyzer (USA) to determine the BET specific surface area and the pore volume of samples. The crystalline structure of samples was confirmed by X-ray diffraction (XRD) (RINT 2400 diffract meter, Rigaku, Japan). Thermogravimetric analysis (TGA) was carried out on Shimadzu DTG-60 instrument. After drying at $100{ }^{\circ} \mathrm{C}$ for $1 \mathrm{~h}$, the catalysts were heated in the $\mathrm{N}_{2}$ atmosphere from $100{ }^{\circ} \mathrm{C}$ to $800^{\circ} \mathrm{C}$ at a rate of $5^{\circ} \mathrm{C} / \mathrm{min}$. Fourier transform infrared spectrometry (FTIR) (Thermo Nicolet NEXUS 670, USA) and X-ray photoelectron spectroscopy (XPS) (Thermo Scientific ESCALAB 250Xi, USA) were employed to characterize the surface oxygen-containing functional groups on the catalysts.

Temperature programmed desorption (TPD) and CO temperature programmed desorption (CO-TPD) were carried out on the catalyst analyzer BELCAT-B-TT (BEL Co. Ltd., Japan) equipped with a thermal conductivity detector (TCD) and a mass spectrometry (BELmass). For 
CO-TPD, sample was first pretreated in He flow at $150{ }^{\circ} \mathrm{C}$ for $1 \mathrm{~h}$, cooled to $40{ }^{\circ} \mathrm{C}$, then to be saturated with $\mathrm{CO}$ for $1 \mathrm{~h}$. Samples were subsequently purged with helium gas at $40{ }^{\circ} \mathrm{C}$ for some time to remove physical adsorption of $\mathrm{CO}$ until no $\mathrm{CO}$ signal in the effluent could be detected by TCD. CO-TPD profiles were obtained by heating the sample at a heating rate of $10{ }^{\circ} \mathrm{C} / \mathrm{min}$ in $\mathrm{He}$ flow. On the other hand, TPD curves were recorded with the same manner as CO-TPD without pre-absorption of $\mathrm{CO}$. The desorbed products were $\mathrm{CO}$ and $\mathrm{CO}_{2}$ as detected by mass spectrometry. In order to eliminate the decomposition of surface groups on catalysts, the curves of desorbed $\mathrm{CO}$ and $\mathrm{CO}_{2}$ in $\mathrm{CO}-\mathrm{TPD}$ subtracted those data from TPD.

\subsection{Catalytic activity test}

The hydroformylation reaction was conducted at $70{ }^{\circ} \mathrm{C}$ in an autoclave under continuous stirring. $0.10 \mathrm{~g}$ of catalyst and $3.73 \mathrm{~g}$ of 1 -hexene were loaded into the autoclave. After flux with 1.0 MPa syngas thrice to purge the residual air, 5.0 MPa syngas was sealed in the reactor at the room temperature. The molar ratio of the utilized syngas was $\mathrm{CO}: \mathrm{H}_{2}=1: 1$. After the reaction, the liquid products were analyzed quantitatively by a gas chromatograph (Shimadzu GC2014) equipped with a capillary column (InertCap 5, length: $30 \mathrm{~m}$ ) and a flame ionization detector (FID).

\section{Results and discussion}

The $\mathrm{N}_{2}$ adsorption/desorption isotherms obtained at $77 \mathrm{~K}$ for $\mathrm{AC}, \mathrm{Rh} / \mathrm{AC}$ and treated $\mathrm{Rh} / \mathrm{AC}$ catalysts were shown in Figure S1 (Supplementary material). All samples exhibited typical type-I isotherm according to IUPAC classification, which was the characteristic of microporous material. The BET specific surface area and pore data calculated from the isotherms were listed in Table 1. The specific surface area and pore volume of $\mathrm{Rh} / \mathrm{AC}$ catalyst were slightly larger than those of raw $\mathrm{AC}$, indicated that the low loading amount and fine dispersion of $\mathrm{Rh}$ did not block the pore 
of raw $\mathrm{AC}$ and the reduction process further developed the pore structure of raw AC. After being treated by nitric acid, the surface areas and pore volumes of treated $\mathrm{Rh} / \mathrm{AC}$ catalysts decreased little with the increasing treatment temperature. This slight decrease could be attributed to the increase of catalyst mass due to the introduction of oxygen by treatment, which led to the relative decrease of the surface area and pore volume of per unit mass catalyst. In addition, the decrease was very limited and negligible, indicating that the nitric acid treatment did not destroy the structure of Rh/AC. The similar result could also be obtained by XRD. The XRD patterns of these catalysts were compared in Figure S2 (Supplementary material). After nitric acid treatment, the crystalline structures of treated $\mathrm{Rh} / \mathrm{AC}$ catalysts were similar to that of the raw $\mathrm{Rh} / \mathrm{AC}$ catalyst.

Nitric acid treatment can introduce a significant number of oxygen-containing functional groups onto the carbon surface, which include carboxylic, lactone, phenolic hydroxyl and so on.[30, 31] Due to the pyrolysis of these introduced groups, the thermal weight losses of materials are different which can be investigated by TGA in $\mathrm{N}_{2}$. As compared in Figure 1, it was obvious that the weight losses of treated-catalysts gradually became larger with the increasing treatment temperature, indicating that the amount of surface oxygen-containing functional groups on $\mathrm{Rh} / \mathrm{AC}$ increased with the increasing treatment temperature.

As an effective technique to characterize surface properties of carbon materials, [31-35] TPD was also used to investigate the difference of samples before and after the surface treatment. The TPD profiles of catalysts were displayed in Figure 2. The raw $\mathrm{Rh} / \mathrm{AC}$ catalyst exhibited only one peak at the lower temperature of $230{ }^{\circ} \mathrm{C}$, which might be attributed to $\mathrm{CO}_{2}$ decomposed from carboxylic acid group on the AC.[34] Different from the raw Rh/AC, the treated catalysts exhibited multiple peaks, due to the increasing groups after treated by nitric acid. Except the broad peak at temperature lower than $300{ }^{\circ} \mathrm{C}$, the broad peak around $640{ }^{\circ} \mathrm{C}$ belonged to the 
lactone groups or carbonyl groups, and the peak at $350{ }^{\circ} \mathrm{C}$ of $\mathrm{Rh} / \mathrm{AC}-80$ could be attributed to anhydride.[31, 33]

The surface properties of $\mathrm{Rh} / \mathrm{AC}$ before and after the surface treatment were also characterized by FTIR, as shown in Figure 3. For the raw $\mathrm{Rh} / \mathrm{AC}$ catalyst, there was only one peak of $-\mathrm{OH}$ at $3430 \mathrm{~cm}^{-1}$, and there existed no obvious peaks for other oxygen-containing functional groups, indicating the low content of oxygen on the surface of $\mathrm{Rh} / \mathrm{AC}$. After being treated by nitric acid, some new peaks appeared on the modified $\mathrm{Rh} / \mathrm{AC}$ catalysts, such as $\mathrm{C}-\mathrm{O}$ (epoxy) at $1220 \mathrm{~cm}^{-1}, \mathrm{C}=\mathrm{O}$ (quinone or ionoradical structure) at $1583 \mathrm{~cm}^{-1}$ and $\mathrm{C}=\mathrm{O}$ (carbonyl or carboxyl) at $1716 \mathrm{~cm}^{-1}$ (Rh/AC-60 and $\left.\mathrm{Rh} / \mathrm{AC}-80\right)$.[36] This indicated that more oxygen-containing groups were introduced on $\mathrm{Rh} / \mathrm{AC}$ surface after nitric acid treatment. To improve understanding the changes of surface oxygen-containing functional groups on catalysts before and after the treatment, XPS was employed to investigate the surface property. As shown in Figure 4(a), the surface oxygen content increased along with the increasing treated temperature. The surface oxygen content of $\mathrm{Rh} / \mathrm{AC}-80$ was as high as 23.81 at\%, much higher than 9.12 at\% of untreated $\mathrm{Rh} / \mathrm{AC}$, demonstrating the introduction of large number of oxygen-containing groups successfully after treatment, being coincided well with the results obtained by TGA. Moreover, for raw $\mathrm{Rh} / \mathrm{AC}$ catalyst, $\mathrm{Rh}$ exhibited two states as $\mathrm{Rh}^{0}(307.1 \mathrm{eV})$ and $\mathrm{Rh}^{+}(308.3 \mathrm{eV})$ in Figure 4(b). Both $\mathrm{Rh}^{0}$ and $\mathrm{Rh}^{+}$are active for the hydroformylation reaction. Moreover, a certain amount of $\mathrm{Rh}^{1+}$ is beneficial to the $\mathrm{CO}$ insertion and the suppression of hydrogenation, which can improve the reaction rate and activity for 1-alkene hydroformylation.[37, 38] Even after being treated by nitric acid, the state of $\mathrm{Rh}$ had almost no difference between raw $\mathrm{Rh} / \mathrm{AC}$ and $\mathrm{Rh} / \mathrm{AC}-80$, being attributed to the resistance of $\mathrm{Rh}$ to $\mathrm{HNO}_{3}$. Based on avoiding the oxidation and loss of $\mathrm{Rh}$ metal, the treatment by $\mathrm{HNO}_{3}$ could produce abundant oxygen-containing functional groups effectively. C1s and O1s peaks were fitted to analyze the categories and amounts of 
functional groups on catalysts as presented in Figure 4(c) and 4(d), respectively. As in Figure 4(c), the binding energies of 284.3 and $285.2 \mathrm{eV}$ were assigned for the $\mathrm{C}=\mathrm{C}$ and $\mathrm{C}-\mathrm{C}$ bonds, respectively. And the binding energies of $286.4,287.5$ and $288.8 \mathrm{eV}$ were attributed to the C-O, $\mathrm{C}=\mathrm{O}$, and $\mathrm{O}=\mathrm{C}-\mathrm{OH}$ oxygen-containing functional groups.[34, 35, 39, 40] Table 1 listed the total amount and relative contents of these groups obtained from TPD and XPS C1s spectra, respectively. It is clear that the amount of functional groups increased obviously with the increasing of treated temperature. Especially, the relative contents of $\mathrm{C}=\mathrm{O}$ and $\mathrm{O}=\mathrm{C}-\mathrm{OH}$ for $\mathrm{Rh} / \mathrm{AC}-80$ become much larger than those of $\mathrm{Rh} / \mathrm{AC}$. The similar results can be observed from the O1s XPS spectra as in Figure 4(d). The peaks of $\mathrm{C}=\mathrm{O}$ in esters, carbonyls and carboxyl $(531.0-532.5 \mathrm{eV})$ increased obviously.

The catalytic performances of 1-hexenehydroformylation over various catalysts were compared in Figure 5 and Figure 6. Figure 5 showed the effect of reaction time on the conversion of 1-hexene over various catalysts. For all catalysts, the conversion of 1-hexene increased with increasing reaction time. However, compared to raw $\mathrm{Rh} / \mathrm{AC}$ catalyst, the conversions of these modified catalysts decreased slightly with the increased treatment temperature under the same reaction time. There are two main probable reasons for this decrease: 1) the increase of oxygen content led to the relative decrease of Rh content in $0.1 \mathrm{~g}$ catalyst $(5.05 \%, 4.84 \%, 4.59 \%$ and $4.22 \%$ for $\mathrm{Rh} / \mathrm{AC}, \mathrm{Rh} / \mathrm{AC}-40, \mathrm{Rh} / \mathrm{AC}-60$ and $\mathrm{Rh} / \mathrm{AC}-80$ respectively); 2) the increase of support's hydrophilicity reduced the diffusion rate of 1-hexene in the pores of AC. Although the conversions of the modified catalysts were slightly lower than that of the raw $\mathrm{Rh} / \mathrm{AC}$ catalyst, they exhibited higher selectivity of n-heptanal and lower selectivity of hexane as shown in Figure 6.

With the increased treatment temperature, the $n / i$ ratio of heptanal was enhanced significantly. After treatment by nitric acid at $80{ }^{\circ} \mathrm{C}$ for $4 \mathrm{~h}, \mathrm{Rh} / \mathrm{AC}-80$ showed the highest 
selectivity of linear product and the $\mathrm{n} / \mathrm{i}$ value of heptanalreached2.3, higher than $1.2 \mathrm{of} \mathrm{Rh} / \mathrm{AC}$. The increased $\mathrm{n} / \mathrm{i}$ ratio should be attributed to the added functional groups, especially the carbonyl or carboxylgroup. According to the Wilkinson's dissociative hydroformylation mechanism, the key step to control aldehyde regioselectivity was the hydride addition step as shown in Scheme 2.[41, 42] In order to improve the selectivity of n-aldehyde, hydrogenation to the $\mathrm{C}$ at $\beta$ position ( $\beta$-C) of 1-alkeneshould be expected, as in Scheme 2. However, according to the Markovnikov's rule, the $\mathrm{H}$ was easier to be attached to the carbon with more $\mathrm{H}$ atoms, which likely resulted in the addition of $\mathrm{H}$ to the $\mathrm{C}$ at aposition $(\alpha-\mathrm{C})$ of 1-alkene during the hydride addition step.[43, 44] $\mathrm{C}=\mathrm{O}$ groups could absorb and conjugate with $\mathrm{C}=\mathrm{C}$ of 1-hexene connected with $\mathrm{Rh}$, indirectly affecting the action of $\mathrm{Rh}$ on the rate and the regioselectivity of the reaction. After being treated by nitric acid, these introduced oxygen-containing functional groups around the Rh active sites might conjugate with $\alpha$-C of 1-alkene connected with Rh (Scheme 3). Acting as electron-withdrawing groups, these carboxyl or carbonyl groups increased the negative charge of $\alpha-\mathrm{C}$ under the action of inductive effect. The intermediate formed from hydrogenation of $\alpha-\mathrm{C}$ in this state was unstable. Therefore, during the hydride addition step, $\mathrm{Rh}$ might add the $\mathrm{H}$ to $\beta$-C of 1-alkene to form a more stable intermediate, which altered the catalytic action of $\mathrm{Rh}$ and achieved an anti-Markovnikov's structure, in favor of n-heptanal production and boosted up the $\mathrm{n} / \mathrm{i}$ ratio of heptanal.

It is necessary to point out that the treated catalysts effectively suppressed production of hexane, which was a common byproduct inhydroformylation of 1-hexene. The selectivity of hexane over treated catalysts was lower than that of raw $\mathrm{Rh} / \mathrm{AC}$. It could be also attributed to the existence of the surface oxygen-containing functional groups, which affected the chemisorbed $\mathrm{CO}$ on $\mathrm{Rh}$ catalyst. It was reported that the thermal desorption pattern of the chemisorbed $\mathrm{CO}$ on supported metal catalysts was correlated closely with their catalytic activities for hydrogenation 
and hydroformylation of alkenes.[45, 46] The chemisorbed $\mathrm{CO}$ on metal usual desorbed in two ways: desorption as $\mathrm{CO}$ at low temperature or desorption as $\mathrm{CO}_{2}$ at high temperature. Desorption of $\mathrm{CO}$ at low temperature indicated the strong carbon-oxygen bond and weak metal-carbon bond, therefore the cleaving of metal-carbon bond $\mathrm{CO}$ and keeping $\mathrm{CO}$ structure would be easy during the reaction. In contrast, desorption of $\mathrm{CO}_{2}$ at high temperature indicated the strong metal-carbon bond and weak carbon-oxygen bond. The strong metal-carbon bond made $\mathrm{CO}$ difficult to desorb while carbon-oxygen bond easy to dissociate. Therefore, desorbed $\mathrm{CO}_{2}$ at high temperature need higher energy for cleaving $\mathrm{CO}$ bond, which was disadvantageous for $\mathrm{CO}$ insert reaction, such as hydroformylation, consequently leading to produce more alkene hydrogenation product. Here CO-TPD-mass was utilized to characterize the $\mathrm{CO}$ desorption behavior of $\mathrm{Rh} / \mathrm{AC}$ and $\mathrm{Rh} / \mathrm{AC}-80$ catalysts.

The results for $\mathrm{CO}_{2}$ and $\mathrm{CO}$ desorption during the TPD were compared in Figure 7.The CO desorption peak located at 77 and $102{ }^{\circ} \mathrm{C}$ for $\mathrm{Rh} / \mathrm{AC}$ and $\mathrm{Rh} / \mathrm{AC}-80$ catalysts, respectively. And the $\mathrm{CO}$ desorption peak of $\mathrm{Rh} / \mathrm{AC}-80$ was rather broader than that of $\mathrm{Rh} / \mathrm{AC}$. The higher desorption temperature and broader peak of $\mathrm{CO}$ desorption for $\mathrm{Rh} / \mathrm{AC}-80$ elucidate the stronger adsorption of $\mathrm{CO}$ on $\mathrm{Rh} / \mathrm{AC}-80$. For $\mathrm{Rh} / \mathrm{AC}$ catalyst, the $\mathrm{CO}_{2}$ desorption peak located at $252{ }^{\circ} \mathrm{C}$. Different from $\mathrm{Rh} / \mathrm{AC}$ catalyst, there was no obvious $\mathrm{CO}_{2}$ desorption peak for $\mathrm{Rh} / \mathrm{AC}-80$ catalyst. It suggests that these introduced oxygen-containing functional groups are disadvantageous for $\mathrm{CO}$ desorbed as $\mathrm{CO}_{2}$, which is alternatively in favor of $\mathrm{CO}$ insert reaction and improving the hydroformylation of 1-hexene.Therefore, the selectivity of hexane decreased from $4.9 \%$ of $\mathrm{Rh} / \mathrm{AC}$ to $0.2 \%$.

The recycling of Rh/AC-80 catalyst in hydroformylation of 1-hexene was tested though four cycles under the same reaction conditions, as shown in Figure 8. It was found that the 1-hexene conversion and products selectivities of the repeated catalyst were maintained after 4 cycles. To 
investigate the leaching of $\mathrm{Rh}$, the Rh loadings of the recycled catalysts after each cycle were determined by ICP. No obvious decrease of Rh loading of Rh/AC-80 after four cycles was observed, demonstrating its reusability. It should be added that the liquid filtered and separated from the reaction mixture after a reaction was added into $5 \mathrm{~mL} 1$-hexene to react under the same reaction conditions but no activity was detected, proving that Rh leaching did not happen.

In order to verify the influence of catalyst's oxygen-containing functional groups on hydroformylation of 1-alkenes, other substrates were used to hydroformylaton reaction. For 1-heptene, 1-octene and 1-decene, the $\mathrm{n} / \mathrm{i}$ ratios of aldehydes obtained by $\mathrm{Rh} / \mathrm{AC}-80$ catalyst were higher than those of $\mathrm{Rh} / \mathrm{AC}$ catalyst as shown in Figure 9.

\section{Conclusions}

$\mathrm{Rh} / \mathrm{AC}$ catalyst was treated by $\mathrm{HNO}_{3}$ at varied temperatures to implant oxygen-containing functional groups. These catalysts were investigated to clarify the influence of catalyst's oxygen-containing functional groups on hydroformylation of 1-hexene for the first time. These oxygen-containing functional groups could alter the surface property of catalysts, thus affect the adsorption and reaction between the active sites and reactants, which was beneficial to improve the selectivity of n-heptanal in hydroformylation. Therefore, the treated catalysts exhibited enhanced n/i ratio of heptanal. Especially $\mathrm{Rh} / \mathrm{AC}$ catalyst treated by $\mathrm{HNO}_{3}$ at $80{ }^{\circ} \mathrm{C}$ realized the highest $\mathrm{n} / \mathrm{i}$ ratio as 2.3 , demonstrating that more functional groups were promotional to enlarge the $\mathrm{n} / \mathrm{i}$ ratio of heptanal. Moreover, more functional groups on the catalyst could suppress hydrogenation of hexene and decrease the selectivity of hexane. These findings disclosed that modifying the surface property of catalysts could control selectivity of products in heterogeneous hydroformylation, which might bring a new insight into the future research of heterogeneous hydrofromylation. 


\section{Acknowledgement}

Financial aids from National Natural Science Foundation of China (21528302) and CREST project of Japan Science and Technology Agency as well as China Scholarship Council are greatly appreciated.

\section{References}

[1] E.V. Gusevskaya, J. Jiménez-Pinto, A. Börner, ChemCatChem 6 (2014) 382-411.

[2] R. Franke, D. Selent, A. Börner, Chem. Rev. 112 (2012) 5675-5732.

[3] P.W.N.M. van Leeuwen, in: P.W.N.M. Van Leeuwen, C. Claver (Eds.), Rhodium Catalyzed Hydroformylation, Springer Netherlands, Dordrecht, 2002, pp. 1-13.

[4] J. Pospech, I. Fleischer, R. Franke, S. Buchholz, M. Beller, Angew. Chem. Int. Ed. 52 (2013) 2852-2872.

[5] M. Vilches-Herrera, L. Domke, A. Börner, ACS Cataly. 4 (2014) 1706-1724.

[6] M. Torrent, M. Solà, G. Frenking, Chem. Rev. 100 (2000) 439-494.

[7] H. Klein, R. Jackstell, K.-D. Wiese, C. Borgmann, M. Beller, Angew. Chem. Int. Ed. 40 (2001) 3408-3411.

[8] P.C.J. Kamer, J.N.H. Reek, P.W.N.M. van Leeuwen, in: P.W.N.M. Van Leeuwen, C. Claver (Eds.), Rhodium Catalyzed Hydroformylation, Springer Netherlands, Dordrecht, 2002, pp. 35-62. [9] P.C.J. Kamer, A. van Rooy, G.C. Schoemaker, P.W.N.M. van Leeuwen, Coordin. Chem. Rev. 248 (2004) 2409-2424.

[10] P.C.J. Kamer, J.N.H. Reek, P.W.N.M. van Leeuwen, in: B. Heaton (Eds.), Mechanisms in Homogeneous Catalysis: A Spectroscopic Approach, Wiley-VCH Verlag GmbH \& Co. KGaA, 2005, pp. 231-269.

[11] S.C. Bourque, F. Maltais, W.-J. Xiao, O. Tardif, H. Alper, P. Arya, L.E. Manzer, J. Am. Chem. 
Soc. 121 (1999) 3035-3038.

[12] C. De, R. Saha, S.K. Ghosh, A. Ghosh, K. Mukherjee, S.S. Bhattacharyya, B. Saha, Res. Chem. Intermed. 39 (2013) 3463-3474.

[13] H. Fu, M. Li, H. Chen, X. Li, J. Mol. Catal. A: Chem. 259 (2006) 156-160.

[14] I.T. Horváth, J. Rábai, Science 266 (1994) 72-75.

[15] M. Haumann, A. Riisager, Chem. Rev. 108 (2008) 1474-1497.

[16] S.K. Sharma, P.A. Parikh, R.V. Jasra, J. Mol. Catal. A: Chem. 316 (2010) 153-162.

[17] X. Li, Y. Zhang, M. Meng, G. Yang, X. San, M. Takahashi, N. Tsubaki, J. Membr. Sci. 347 (2010) 220-227.

[18] S. Alini, A. Bottino, G. Capannelli, A. Comite, S. Paganelli, Appl. Catal. A: Gen. 292 (2005) 105-112.

[19] T. Van Vu, H. Kosslick, A. Schulz, J. Harloff, E. Paetzold, M. Schneider, J. Radnik, N. Steinfeldt, G. Fulda, U. Kragl, Appl. Catal. A: Gen. 468 (2013) 410-417.

[20] M. Tan, G. Yang, T. Wang, T. Vitidsant, J. Li, Q. Wei, P. Ai, M. Wu, J. Zheng, N. Tsubaki, Catal. Sci. Technol. 6 (2016) 1162-1172.

[21] M. Hassam, A. Taher, G.E. Arnott, I.R. Green, W.A.L. van Otterlo, Chem. Rev. 115 (2015) 5462-5569.

[22] H. Wakamatsu, M. Nishida, N. Adachi, M. Mori, J. Org. Chem. 65 (2000) 3966-3970.

[23] A. Behr, H. Witte, Z. Bayrak, Eur. J. Lipid Sci. Technol. 115 (2013) 721-728.

[24] H.K. Reinius, A.O.I. Krause, Catal. Lett. 70 (2000) 149-154.

[25] C.P. Casey, E.L. Paulsen, E.W. Beuttenmueller, B.R. Proft, L.M. Petrovich, B.A. Matter, D.R. Powell, J. Am. Chem. Soc. 119 (1997) 11817-11825.

[26] I. Ogino, Y. Suzuki, S.R. Mukai, ACS Catal. 5 (2015) 4951-4958.

[27] S. Dong Jin, P. Tae-Jin, I. Son-Ki, Carbon 31 (1993) 427-435. 
[28] G. Zhang, Z. Li, H. Zheng, T. Fu, Y. Ju, Y. Wang, Appl. Catal. B: Environ. 179 (2015) 95-105.

[29] Q. Li, H. Yang, Z. Ma, X. Zhang, Catal. Commun. 17 (2012) 8-12.

[30] H. ShamsiJazeyi, T. Kaghazchi, J. Ind. Eng. Chem. 16 (2010) 852-858.

[31] M.S. Shafeeyan, W.M.A.W. Daud, A. Houshmand, A. Shamiri, J. Anal. Appl. Pyrol. 89 (2010) 143-151.

[32] C. Moreno-Castilla, M.A. Ferro-Garcia, J. Rivera-Utrilla, J.P. Joly, Energy Fuels 8 (1994) 1233-1237.

[33] J.L. Figueiredo, M.F.R. Pereira, M.M.A. Freitas, J.J.M. Órfão, Carbon 37 (1999) 1379-1389. [34] P. Brender, R. Gadiou, J.-C. Rietsch, P. Fioux, J. Dentzer, A. Ponche, C. Vix-Guterl, Anal. Chem. 84 (2012) 2147-2153.

[35] J. Zhou, Z. Sui, J. Zhu, P. Li, D. Chen, Y. Dai, W. Yuan, Carbon 45 (2007) 785-796.

[36] C. Yu, X. Fan, L. Yu, T.J. Bandosz, Z. Zhao, J. Qiu, Energy Fuels 27 (2013) 1499-1505.

[37] T.A. Kainulainen, M.K. Niemelä, A.O.I. Krause, J. Mol. Catal. A: Chem. 140 (1999) 173-184.

[38] S.S.C. Chuang, S.I. Pien, J. Catal. 135 (1992) 618-634.

[39] D. Rosenthal, M. Ruta, R. Schlögl, L. Kiwi-Minsker, Carbon 48 (2010) 1835-1843.

[40] D. Yang, A. Velamakanni, G. Bozoklu, S. Park, M. Stoller, R.D. Piner, S. Stankovich, I. Jung, D.A. Field, C.A. Ventrice Jr, R.S. Ruoff, Carbon 47 (2009) 145-152.

[41] D. Evans, J.A. Osborn, G. Wilkinson, J. Chem. Soc. A: Inorg., Phys. Theor. (1968) 3133-3142.

[42] C.K. Brown, G. Wilkinson, J. Chem. Soc. A: Inorg., Phys., Theor. (1970) 2753-2764.

[43] O.N. Temkin, Kinet. Catal. 55 (2014) 172-211.

[44] M. Beller, J. Seayad, A. Tillack, H. Jiao, Angew. Chem. Int. Ed. 43 (2004) 3368-3398. 
[45] X. Qiu, N. Tsubaki, S. Sun, K. Fujimoto, Catal. Commun. 2 (2001) 75-80.

[46] X. Qiu, N. Tsubaki, K. Fujimoto, J. Chem. Eng. Jpn. 34 (2001) 1366-1372. 


\section{Table captions}

Table 1 The pore parameters and surface chemical properties of AC and catalysts 


\section{Scheme captions}

Scheme 1 Hydroformylation and isomerization of 1-hexene

Scheme 2 Schematic diagram of Wilkinson's hydroformylation mechanism

Scheme 3 Schematic diagram of the influence of groups on hydroformylation 


\section{Figure captions}

Figure 1 TGA curves of catalysts in $\mathrm{N}_{2}$

Figure 2 TPD profiles of catalysts

Figure 3 FTIR spectra of catalysts

Figure 4 Surface oxygen content obtained from XPS (a) and typical XPS spectra of catalysts:

Rh3d (b), C1s (c), and O1s (d)

Figure 5 The effect of reaction time on the conversion of 1-hexene over varied catalysts. Reaction conditions: $0.1 \mathrm{~g}$ catalyst, $3.73 \mathrm{~g}$ 1-hexene, $70{ }^{\circ} \mathrm{C}, 5 \mathrm{MPa}, \mathrm{H}_{2}: \mathrm{CO}=1: 1$

Figure 6 (a) The conversion of 1-hexene and n/i ratio of heptanal of varied catalysts; (b) the products distribution of varied catalysts. Reaction conditions: $0.1 \mathrm{~g}$ catalyst, $3.73 \mathrm{~g}$ 1-hexene, 70 ${ }^{\circ} \mathrm{C}, 1 \mathrm{~h}, 5 \mathrm{MPa}, \mathrm{H}_{2}: \mathrm{CO}=1: 1$

Figure 7 CO-TPD-mass profiles of Rh/AC (a) and Rh/AC-80 (b) catalysts Figure 8 Reusability test of Rh/AC-80 catalyst for hydroformylation of 1-hexene.Reaction conditions: $0.1 \mathrm{~g}$ catalyst, $3.73 \mathrm{~g} 1$-hexene, $70{ }^{\circ} \mathrm{C}, 1 \mathrm{~h}, 5 \mathrm{MPa}, \mathrm{H}_{2}: \mathrm{CO}=1: 1$ Figure 9 The conversion of 1-alkenes and n/i ratios of Rh/AC (a) and Rh/AC-80 (b) catalysts for hydroformylation of other 1 -alkenes. Reaction conditions: $0.1 \mathrm{~g}$ catalyst, $3.73 \mathrm{~g} \mathrm{1-alkenes,} 70{ }^{\circ} \mathrm{C}$, $1 \mathrm{~h}, 5 \mathrm{MPa}, \mathrm{H}_{2}: \mathrm{CO}=1: 1$ 


\begin{tabular}{|c|c|c|c|c|c|c|c|c|c|}
\hline \multirow[t]{2}{*}{ Materials } & \multirow{2}{*}{$\begin{array}{c}\text { Specific surface } \\
\text { area }\left(\mathrm{m}^{2} / \mathrm{g}\right)\end{array}$} & \multicolumn{3}{|c|}{ Pore volume $\left(\mathrm{cm}^{3} / \mathrm{g}\right)$} & \multirow{2}{*}{$\begin{array}{l}\text { Total amount } \\
(\mathrm{mmol} / \mathrm{g})^{\mathrm{a}}\end{array}$} & \multicolumn{4}{|c|}{$\mathrm{C} 1 \mathrm{~s}(\%)^{\mathrm{b}}$} \\
\hline & & Total & Micropore & Mesopore & & $\mathrm{C}=\mathrm{C}(\mathrm{C}-\mathrm{C})$ & $\mathrm{C}-\mathrm{O}$ & $\mathrm{C}=\mathrm{O}$ & $\mathrm{O}=\mathrm{C}-\mathrm{O}$ \\
\hline $\mathrm{AC}$ & 1064 & 0.62 & 0.54 & 0.08 & -- & -- & -- & -- & -- \\
\hline $\mathrm{Rh} / \mathrm{AC}$ & 1145 & 0.67 & 0.56 & 0.11 & 2.15 & 73.1 & 13.0 & 6.3 & 7.6 \\
\hline $\mathrm{Rh} / \mathrm{AC}-40$ & 1017 & 0.63 & 0.48 & 0.15 & 3.82 & 70.3 & 13.1 & 7.7 & 8.9 \\
\hline $\mathrm{Rh} / \mathrm{AC}-60$ & 951 & 0.58 & 0.46 & 0.12 & 4.24 & 70.1 & 13.7 & 8.9 & 10.3 \\
\hline $\mathrm{Rh} / \mathrm{AC}-80$ & 944 & 0.57 & 0.45 & 0.12 & 5.57 & 68.7 & 11.9 & 8.4 & 12.5 \\
\hline
\end{tabular}

${ }^{a}$ The total amount of surface oxygen-containing functional groups obtained by TPD

${ }^{\mathrm{b}}$ The relative contents of functional groups obtained from XPS C1s spectra 


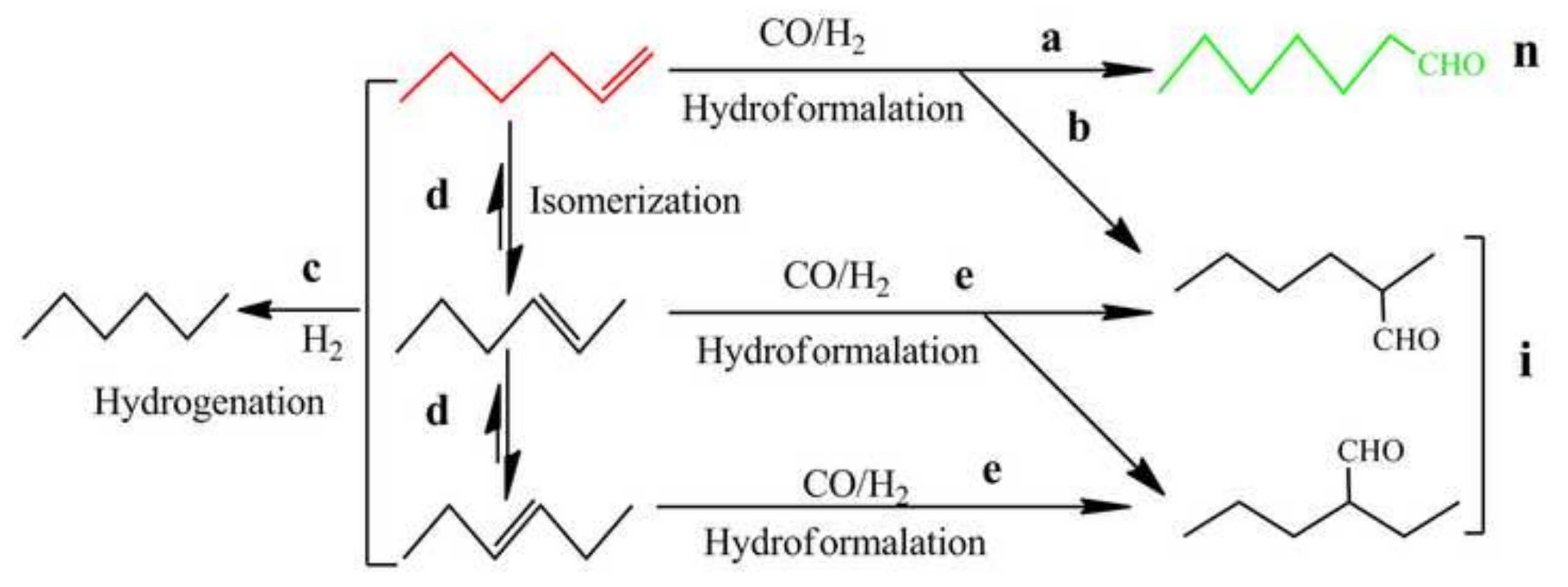

Hydrogenation 


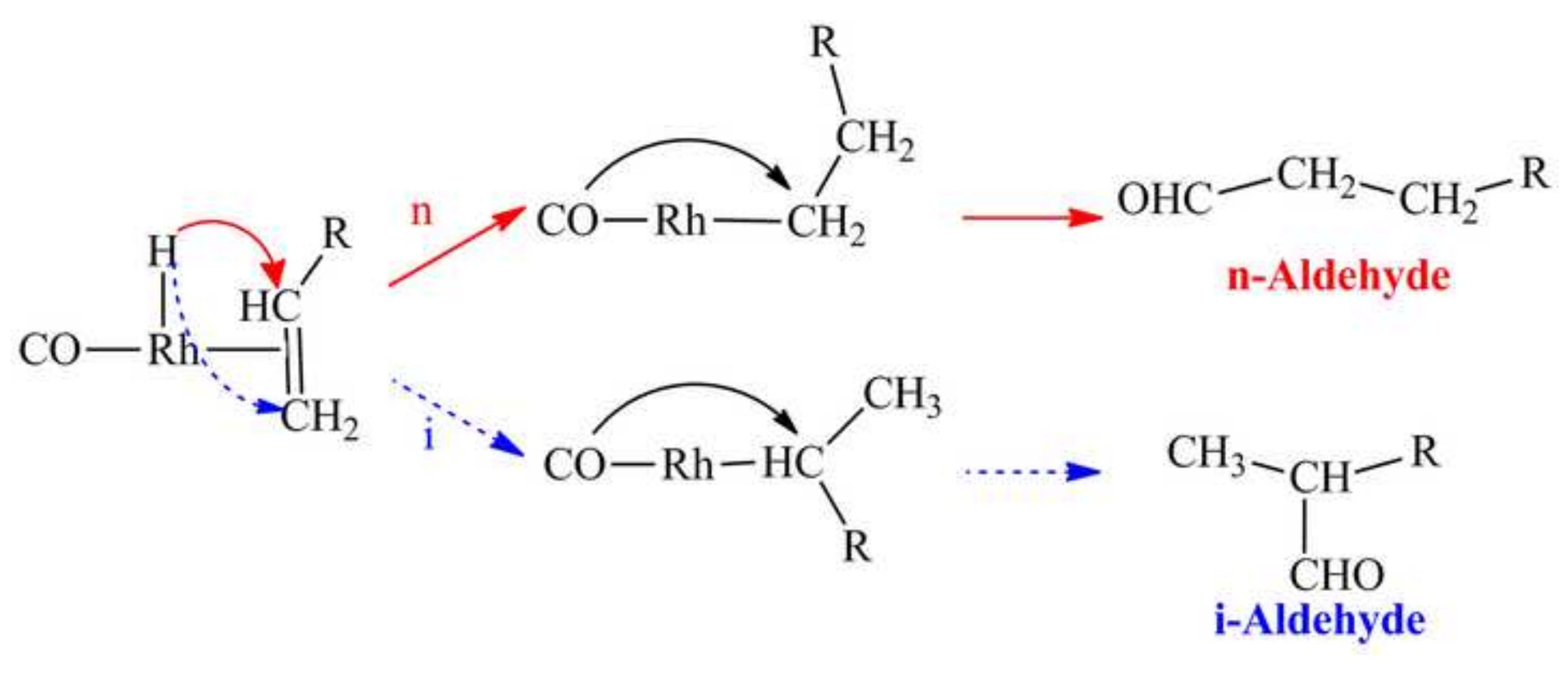


Functional group
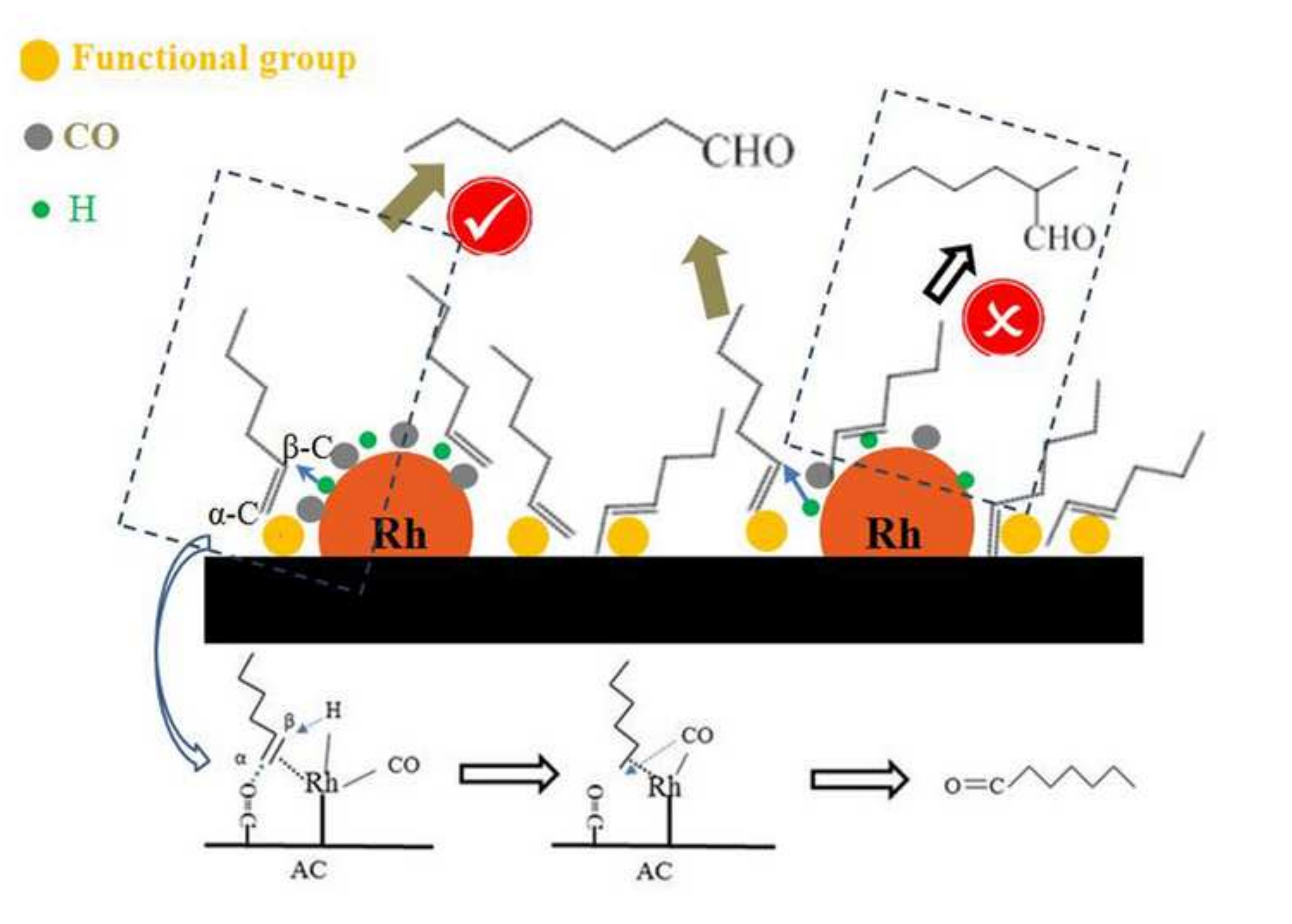


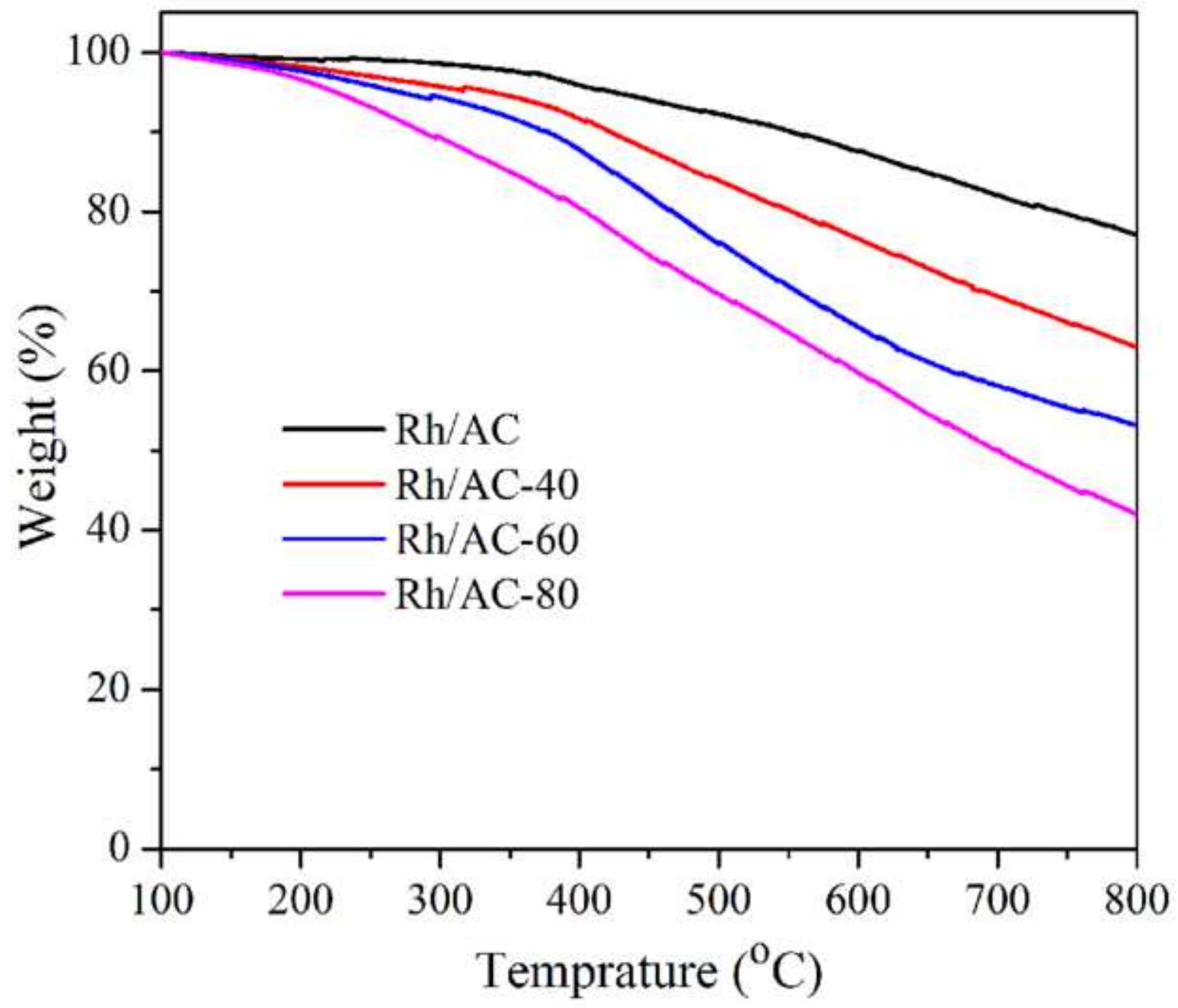




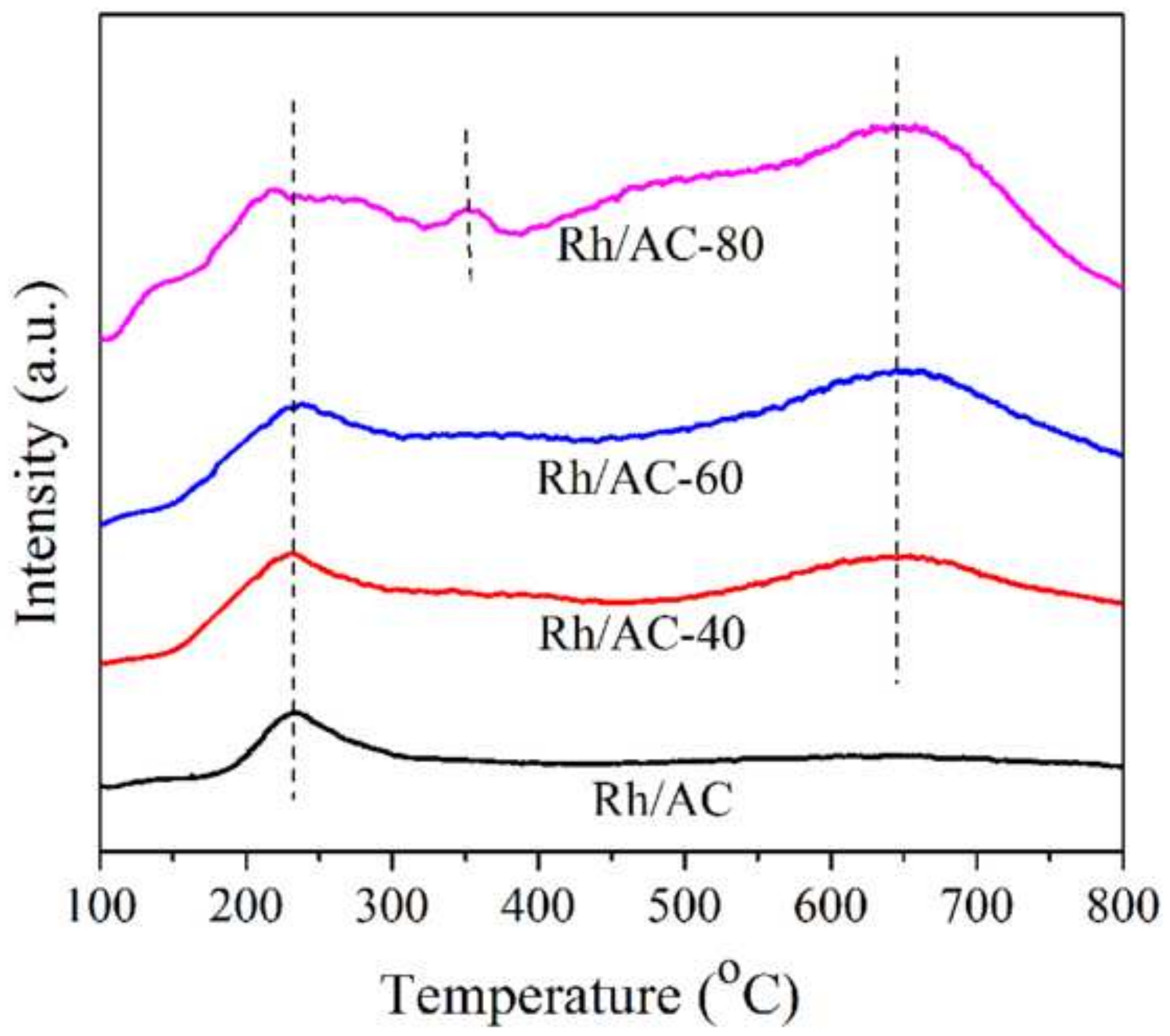




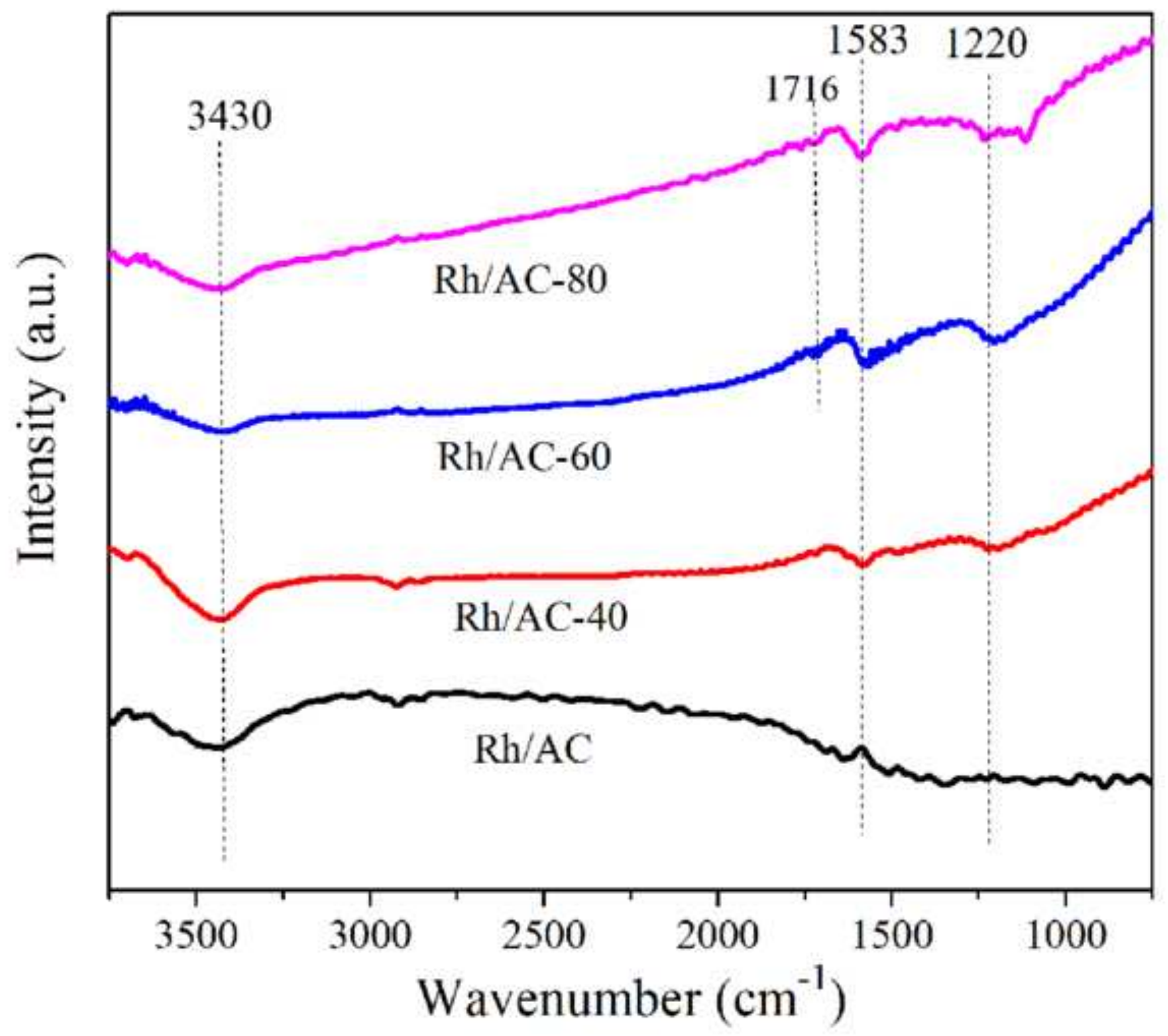



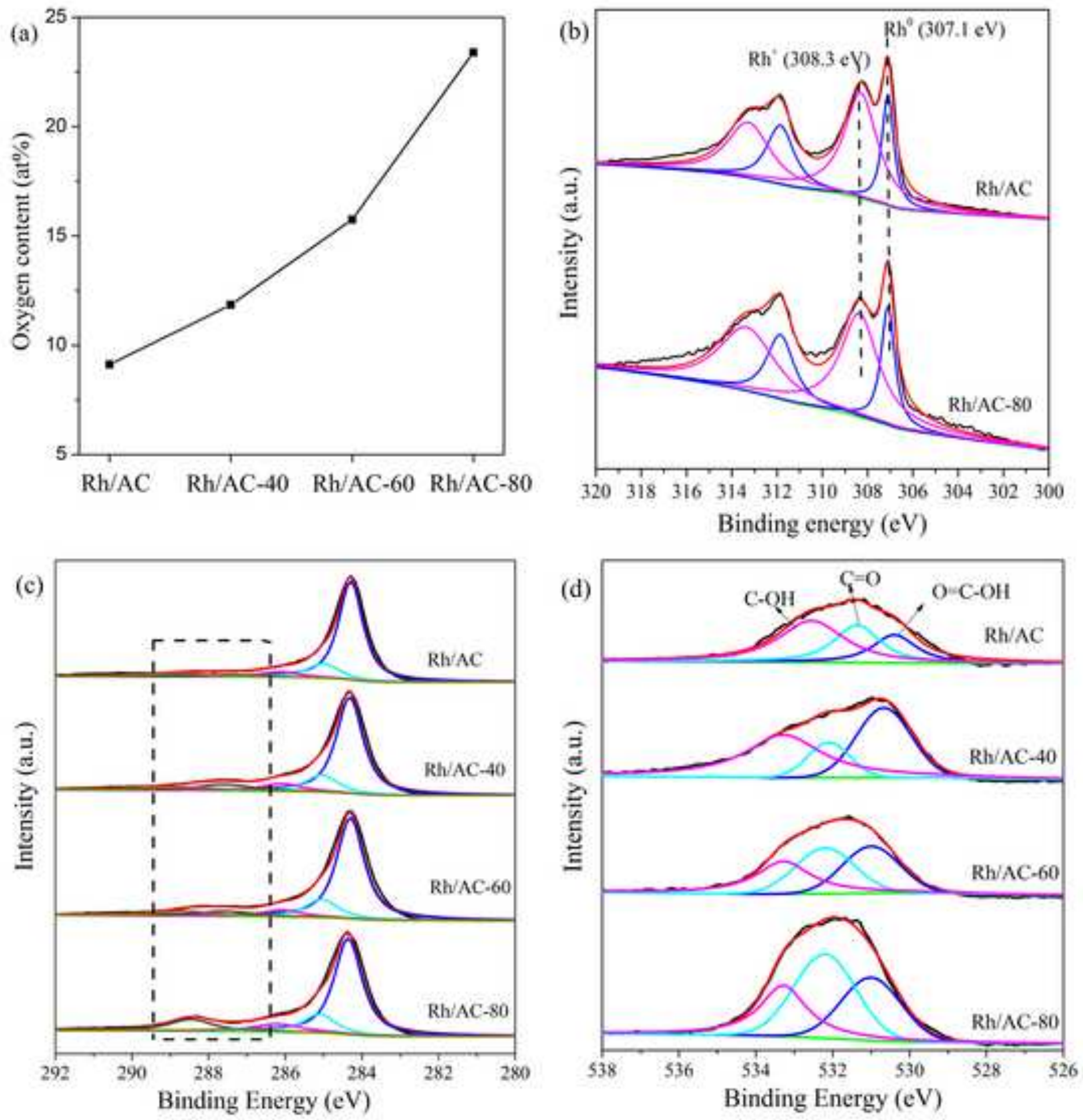


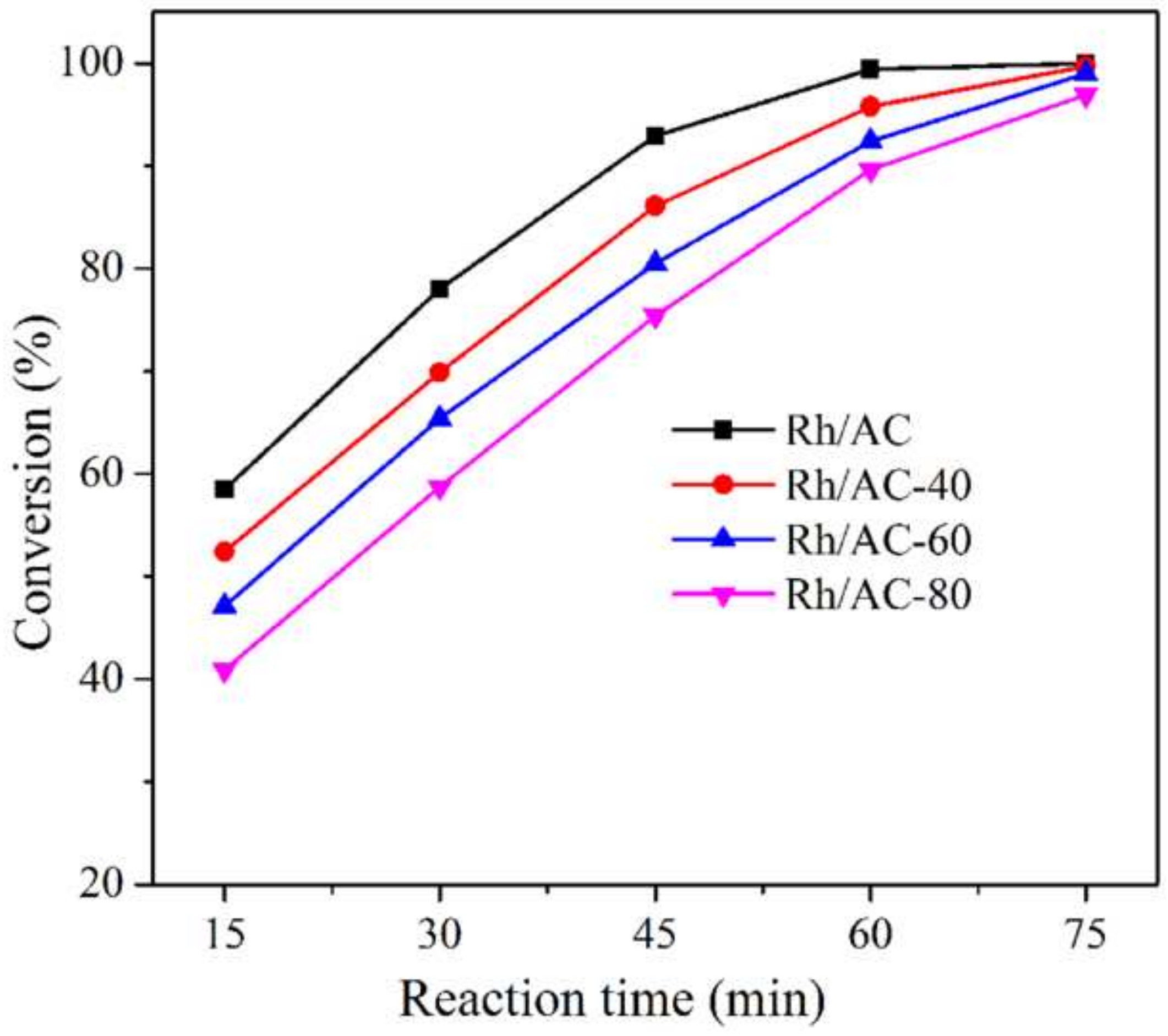




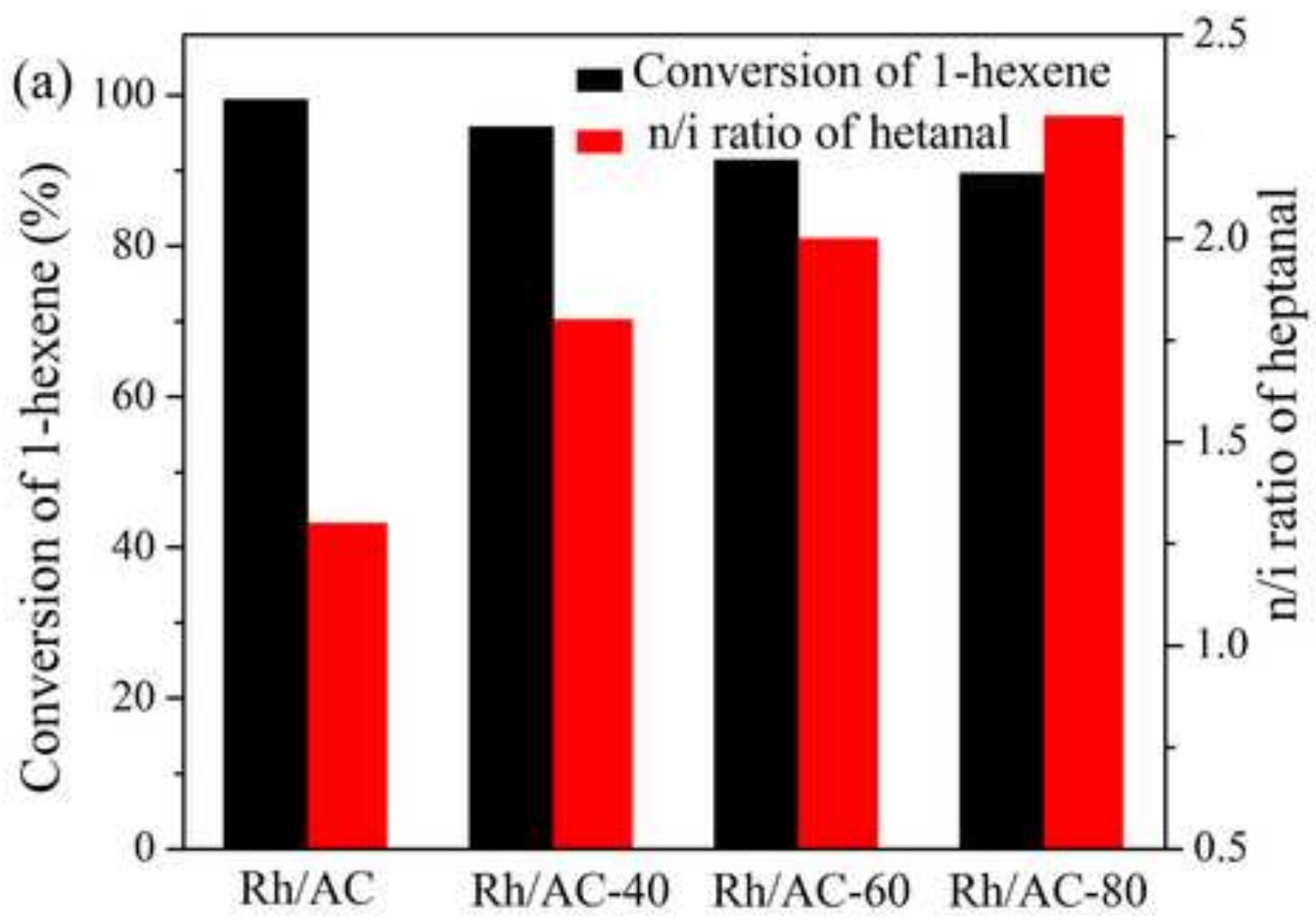

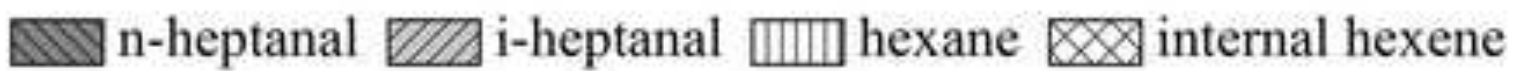

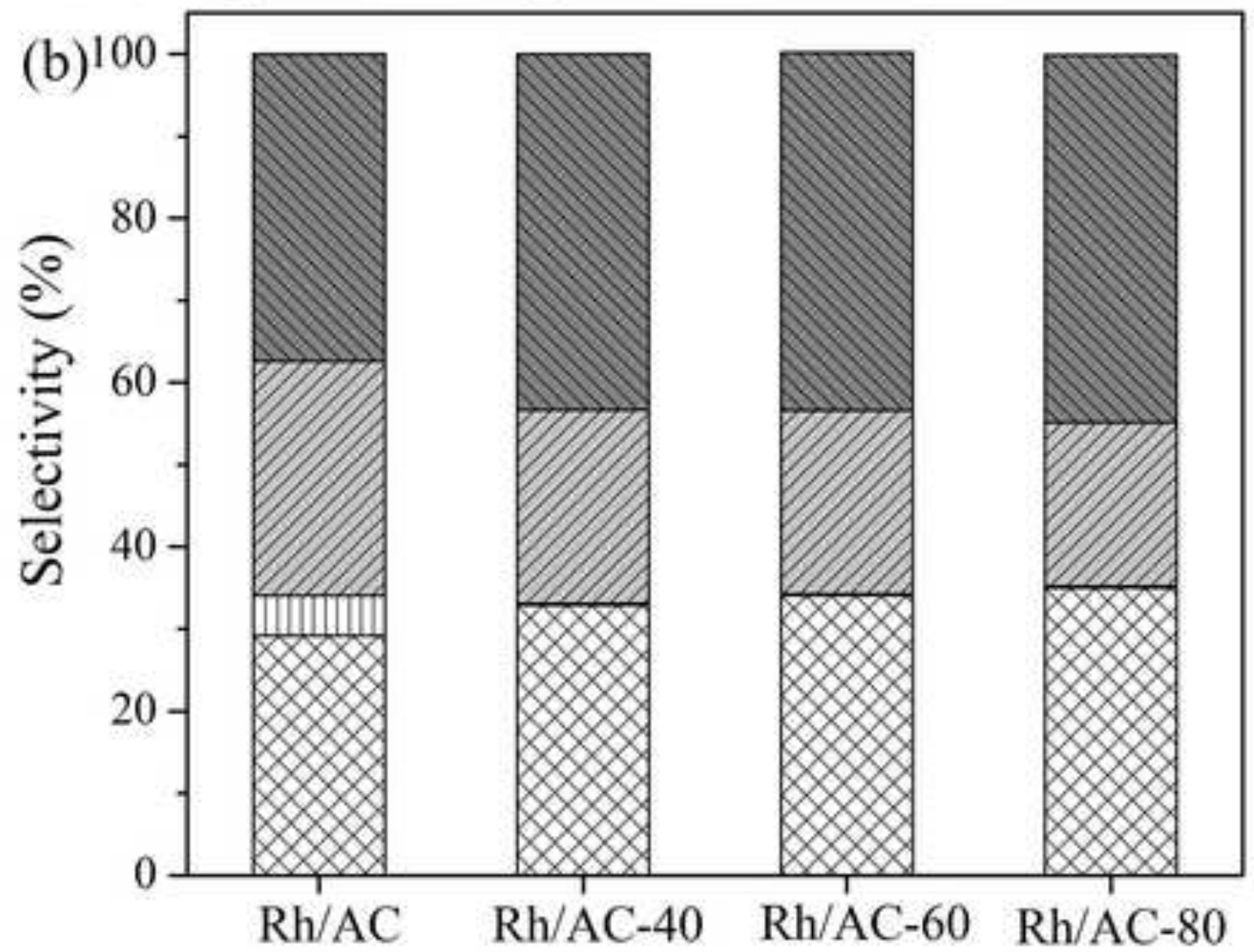



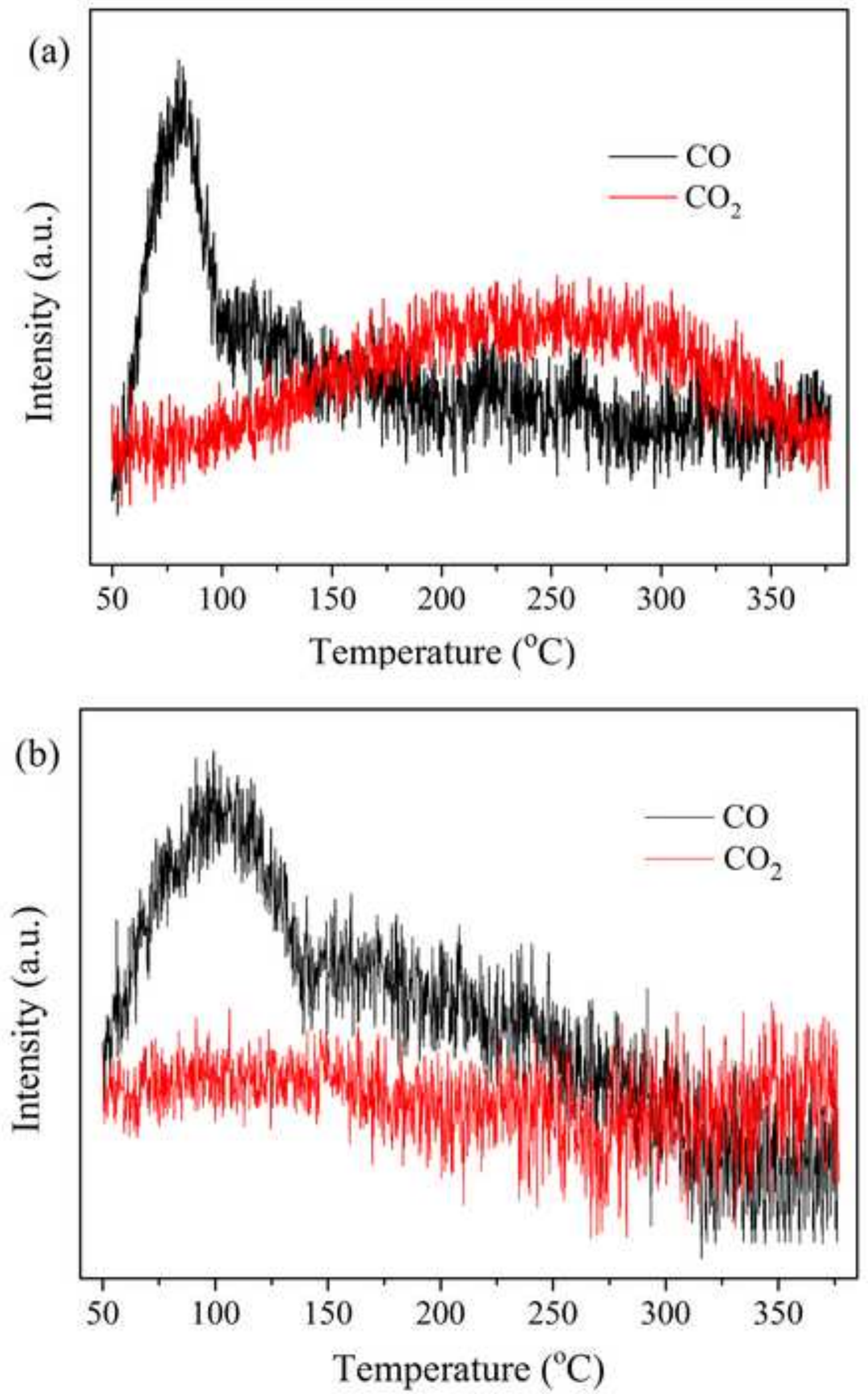


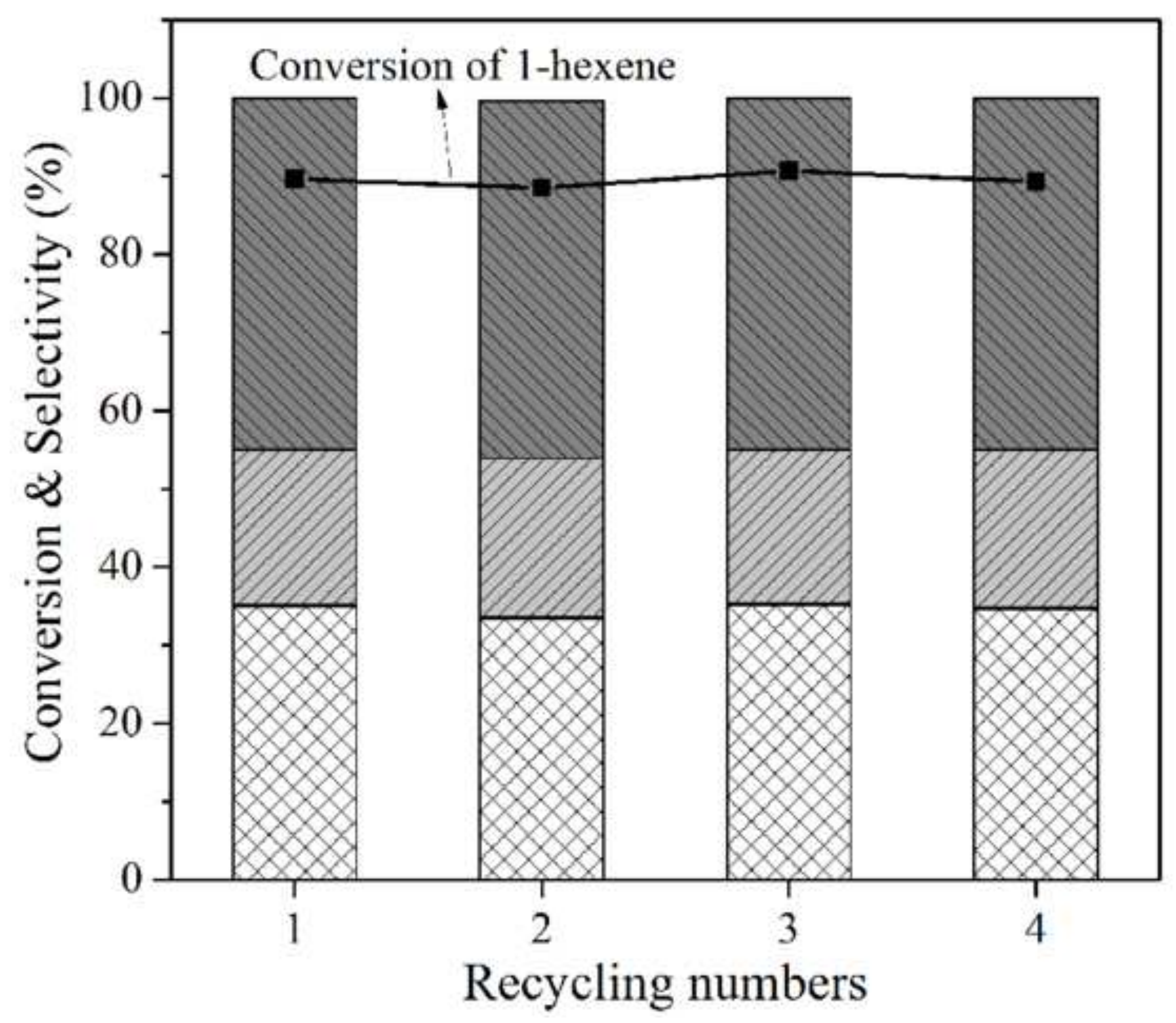


These oxygen-containing functional groups could alter the surface property of catalysts, thus affect the adsorption action and reaction between the active sites and reactants, which was beneficial to improve the selectivity of n-heptanal in hydroformylation.

Functional group

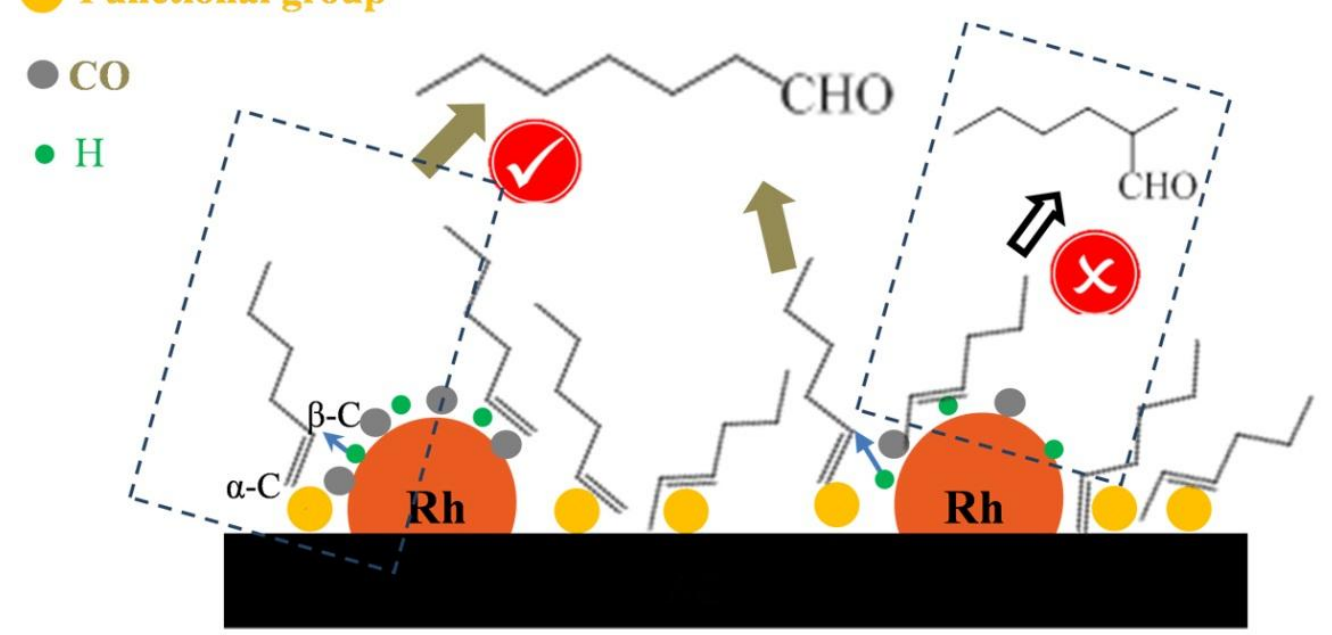

